\title{
Synthesis of Antibodies to Hepatitis B Virus by Cultured Lymphocytes from Chronic Hepatitis B Surface Antigen Carriers
}

\author{
Geoffrey M. Dusheiko, Jay H. Hoofnagle, W. Graham Cooksley, \\ Stephen P. JAMES, and E. ANTHONY Jones, Liver Diseases Section, \\ Digestive Diseases Branch, National Institute of Arthritis, Diabetes, and \\ Digestive and Kidney Diseases, National Institutes of Health, Bethesda, \\ Maryland 20205
}

A B S T R A C T It has been postulated that host immune defects are responsible for the development and persistence of the hepatitis B surface antigen ( $\mathrm{HBsAg}$ ) carrier state. The nature of these defects is unknown, but the absence of a readily detectable antibody response to HBsAg (anti-HBs) may be important. The synthesis of both anti-HBs and antibody to hepatitis $B$ core antigen (anti-HBc) in cultures containing peripheral blood mononuclear cells from chronic HBsAg carriers and from control (antibody-positive) patients was measured in the presence of pokeweed mitogen. Similar amounts of polyclonal IgG and IgM were synthesized by cultures containing lymphocytes from chronic carriers and controls. Anti-HBc was detectable in lymphocyte supernatants from 2 of 20 controls and from 21 of 29 carriers. The presence of anti-HBc synthesis in vitro correlated with high serum titers of anti$\mathrm{HBc}$. In contrast, anti-HBs was detected in lymphocyte supernatants from 6 of 20 controls (predominantly in those who had high serum titers of anti-HBs) but in none of the supernatants from $29 \mathrm{HBsAg}$ carriers.

In order to identify the mechanisms for the lack of detectable anti-HBs synthesis by chronic HBsAg carrier lymphocytes, co-culture experiments were performed using $T$ and $B$ lymphocyte fractions that had been purified by affinity chromatography. B lymphocytes from carriers co-cultured with allogeneic irradiated ("helper") T lymphocytes from controls synthesized normal amounts of IgG, IgM, and anti-HBc

Dr. Dusheiko was the recipient of a South African Research Council Overseas Scholarship. His present address is University of the Witwatersrand Medical School, Department of Medicine, Johannesburg 2001, South Africa. Address reprint requests to Dr. Hoofnagle.

Received for publication 9 April 1982 and in revised form 23 November 1982. but still did not synthesize detectable amounts of antiHBs. In the converse experiments, B lymphocytes from controls were co-cultured with irradiated $\mathrm{T}$ lymphocytes from carriers. The $T$ lymphocytes from 16 of 24 carriers augmented anti-HBs production by control B cells normally, the remaining eight did not. Finally, mixtures of control B cells and control irradiated T lymphocytes were co-cultured with $\mathrm{T}$ lymphocytes from chronic HBsAg carriers. 5 of 12 carriers demonstrated active suppression of anti-HBs production, and in three this suppression was specific, as IgG and IgM production remained normal. We conclude that chronic HBsAg carriers have a specific B lymphocyte defect in anti-HBs production. In addition, defects in the function of regulatory $\mathrm{T}$ lymphocytes may contribute to the absence of anti-HBs synthesis in some HBsAg carriers.

\section{INTRODUCTION}

The outcome of hepatitis B virus infection is variable (1). The majority of persons infected with this virus develop an acute hepatitis from which they make a complete recovery: in them, the hepatitis $B$ virus is cleared, serum hepatitis B surface antigen ( $\mathrm{HBsAg},{ }^{1}$ Australia antigen) disappears, and ultimately antibody to HBsAg (anti-HBs) becomes detectable in serum. However, in a small percentage of persons infected with this virus, hepatitis $B$ virus synthesis persists, the serum remains positive for $\mathrm{HBsAg}$, and the patient

\footnotetext{
'Abbreviations used in this paper: Anti-HBc, antibody to $\mathrm{HBcAg}$; Anti-HBe, antibody to $\mathrm{HBeAg}$; Anti-HBs, antibody to $\mathrm{HBsAg}$; $\mathrm{HBcAg}$, hepatitis $\mathrm{B}$ core antigen; $\mathrm{HBeAg}$, hepatitis B e antigen; HBsAg, hepatitis B surface antigen; PBMC, peripheral blood mononuclear cells; PWM, pokeweed mitogen; RIA, radioimmunoassay.
} 
becomes a chronic HBsAg carrier. The underlying mechanisms (whether viral or host) that lead to the development of the chronic HBsAg carrier state are not known. Host cellular and humoral immune responses are suspected of being important. Thus the chronic carrier state is particularly common among individuals with conditions or diseases associated with significant immunologic hyporesponsiveness, such as newborns, patients receiving immunosuppressive agents or undergoing renal dialysis and patients with Down's syndrome, Hodgkin's disease, acute leukemia, and lepromatous leprosy (2-4). However, the great majority of chronic HBsAg carriers are otherwise normal individuals, in whom no appreciable generalized immunologic deficiency can be demonstrated (5). This fact suggests that the development of the chronic HBsAg carrier state is due to a specific immune defect, such as a defect either in the recognition, processing or response to one of the hepatitis $B$ virus antigens.

In patients who recover from type B hepatitis, antiHBs appears in serum during convalescence (1). AntiHBs also appears to protect against future infection with hepatitis B virus. In contrast, chronic HBsAg carriers do not develop detectable anti-HBs, although they do produce high titers of antibody to hepatitis B core antigen (anti-HBc) and antibody to hepatitis $B$ e antigen (anti-HBe). The absence of anti-HBs, despite the presence of circulating $\mathrm{HBsAg}$, is evidence that these individuals have a specific immunologic unresponsiveness to this antigen that may contribute to their inability to eradicate hepatitis B virus (6). To test this possibility, we have investigated the ability of lymphocytes from chronic HBsAg carriers and from individuals who had recovered from type $B$ hepatitis to produce polyclonal IgG and IgM as well as specific hepatitis $B$ viral antibodies in vitro.

\section{METHODS}

Patients. A total of 46 chronic HBsAg carriers and 28 control individuals were studied. The chronic $\mathrm{HBsAg}$ carriers included 43 men and 3 women, aged 23-61 (mean 36) yr. 38 of the carriers were also positive for hepatitis $\mathrm{B}$ e antigen (HBeAg) and the remaining 8 for anti-HBe. Serum hepatitis B virus specific DNA polymerase was detected in 34 carriers (all of whom were also positive for $\mathrm{HBeAg}$ ). 15 patients also possessed "heterotypic" anti-HBs, i.e. antibody to HBsAg that was directed towards a different subtype than that of the $\mathrm{HBsAg}$ in the same serum (7). 38 of the carriers had undergone a percutaneous liver biopsy within 1-2 yr of the blood sampling for lymphocyte studies: 8 had chronic persistent hepatitis, 19 chronic active hepatitis, and 9 cirrhosis. Two other patients had minor, nonspecific changes in liver biopsy histology without evidence of hepatitis. 28 patients had symptoms, but they were usually mild; the most common symptom was fatigability. Most patients were otherwise healthy. However, two patients had Hodgkin's disease (both were in remission and were not receiving chemotherapy) and two patients had polyarteritis nodosa. Two indi- viduals were receiving corticosteroids at the time of blood sampling. 11 other patients had received corticosteroids or other immunosuppressive therapy in the past.

The 28 control subjects were all $\mathrm{HBs} A g$-negative in serum but were positive for anti-HBs. This group included laboratory personnel, medical care workers, and random patients observed at the National Institutes of Health Clinical Center. 20 of these subjects were reactive for anti- $\mathrm{HBc}$, indicating previous infection with the hepatitis $B$ virus. The eight other subjects were recipients of the hepatitis $B$ virus vaccine and were positive for anti-HBs alone (8). Selected control individuals (both recovered and vaccinated) were studied both before and after booster inoculation with the hepatitis $B$ virus vaccine. The protocol of boosting of individuals with the hepatitis B vaccine had been approved by the Clinical Research and Human Experimentation Committees of the National Institutes of Health Clinical Center and informed consent was obtained.

Separation and culture of lymphocytes. Peripheral blood mononuclear cells (PBMC) were isolated from heparinized venous blood by Ficoll Hypaque density centrifugation (9). After centrifugation, the PBMC were washed once and then incubated at $37^{\circ} \mathrm{C}$ for $1 \mathrm{~h}$ in RPMI medium (Gibco Laboratories, Grand Island Biological Co., Grand Island, NY) supplemented with $25 \mathrm{mM}$ Hepes buffer, 10\% heat-inactivated fetal calf serum, $4 \mathrm{mM}$ L-glutamine and $1 \%$ of stock penicillin-streptomycin $(100 \mathrm{U} / \mathrm{ml}$ and $100 \mu \mathrm{g} / \mathrm{ml}$, respectively) (complete medium). The cells were then washed three times by centrifugation through $10 \mathrm{ml}$ of fetal calf serum in order to elute adherent serum proteins and cytophilic immunoglobulins.

Selected control individuals underwent lymphopheresis and lym phocytes from these individuals were cryopreserved. PBMC from these controls were separated by density centrifugation, washed extensively in complete medium and then frozen in a controlled freezing apparatus (Programmable Freezing System and Vapour Phase Liquid Nitrogen Freezer, Cryo-Med, Mount Clemens, MI) after dilution of the cells in $7.5 \%$ dimethyl sulfoxide in RPMI and $20 \%$ fetal calf serum. Lymphocytes were stored in liquid nitrogen. After thawing, lymphocytes were separated into $T$ and $B$ cell-enriched fractions. PBMC were tested for viability by trypan blue exclusion staining and only those preparations demonstrating $>90 \%$ viability were used in culture experiments.

$T$ and $B$ lymphocyte separation. T and B lymphocyteenriched fractions were isolated by immunoadsorbent affinity chromatography using a Sephadex G-200 rabbit anti-human $\mathrm{F}\left(\mathrm{ab}^{\prime}\right)_{2}$ column (10). Approximately 30-40 $\times 10^{6} \mathrm{PBMC}$ were layered over $8 \mathrm{ml}$ of an anti-F $\left(\mathrm{ab}^{\prime}\right)_{2}$ affinity column $(70 \times 15 \mathrm{~mm})$. The first $15 \mathrm{ml}$ of eluate comprised the $\mathrm{T}$ lymphocyte-enriched fraction. Thereafter, the column was agitated by repeated pipetting and the resulting eluate collected as the B lymphocyte-enriched fraction. T lymphocyte fractions contained an average of $75 \% \mathrm{~T}$ cells, $<1 \% \mathrm{~B}$ cells and 1-2\% esterase-positive cells. The $B$ lymphocyte fractions contained an average of $40 \%$ B cells, $<1 \%$ T cells and $40 \%$ esterase positive cells (10).

Pokeweed mitogen (PWM) stimulation. PBMC were counted using a coulter-counter (Coulter Electronics, Hialeah, FL) and then diluted to an appropriate concentration in complete medium and stimulated with a 1:100 dilution of PWM (Gibco Laboratories, lot A 893306). The lymphocytes were then cultured at $37^{\circ} \mathrm{C}$ in a humidified atmosphere of $5 \% \mathrm{CO}_{2}$ for $10 \mathrm{~d}$. In unseparated PBMC cultures, $2 \times 10^{6}$ cells were cultured in $1 \mathrm{ml}$ of complete medium in loosely capped one-dram glass vials (Wheaton Scientific, Millville, 
NJ). 6-10 replicate cultures were performed on each individual.

In studies of helper (inducer) $T$ cell regulation, $T$ lymphocyte preparations were irradiated with 2,000 rad using a cesium source (Isomedix, Parsipanny, $\mathrm{NJ}$ ) (11). $1.6 \times 10^{6}$ irradiated T lymphocytes were then cultured with $4 \times 10^{5}$ allogenic B lymphocytes in $1 \mathrm{ml}$ of complete medium. This $T: B$ cell ratio (4:1) had been found in pilot experiments to be optimal for pokeweed mitogen stimulated antibody synthesis. These cultures were performed in triplicate.

In studies of suppressor $T$ cell regulation, $8 \times 10^{5}$ nonirradiated T lymphocytes were cultured with $8 \times 10^{5}$ allogeneic irradiated T lymphocytes and $4 \times 10^{5} \mathrm{~B}$ lymphocytes. Thus, in all cultures, the total number of PBMC and the culture volume were kept constant. These cell cultures were also performed in triplicate.

Hepatitis B virus serologic testing. HBsAg was tested by solid-phase radioimmunoassay (RIA) (Ausria-II, Abbott Laboratories, North Chicago, IL). This assay is capable of detecting as little as $200 \mathrm{pg} / \mathrm{ml}$ of $\mathrm{HBsAg}$ protein. Anti-HBs was tested by solid-phase RIA (Ausab, Abbott Laboratories). Results were expressed as RIA units (sample counts per minute/negative control mean counts per minute). RIA ratios were linear in the range of 2.1 to $120 \mathrm{U}$ and were thus used to quantitate the amount of specific anti-HBs produced Complete medium was used as the negative control for assays performed on culture supernatants. In selected samples, the anti-HBs specificity was confirmed by double-antibody radioimmuno-precipitation assay (12). Anti- $\mathrm{HBc}$ was assayed by a blocking radioimmunoassay (Corab: Abbott Laboratories). Results were expressed as a percentage inhibition in comparison to standard positive and negative control samples: Percentage inhibition $=$ sample $\mathrm{cpm}-$ positive control $\mathrm{cpm} /$ negative control $\mathrm{cpm}$ - positive control $\mathrm{cpm} \times 100 \%$. A supernatant was considered positive for anti-HBc if it resulted in $>50 \%$ inhibition. In selected samples, end point dilution titers of anti-HBc were obtained.

Selected serum specimens and supernatants were tested for hepatitis B e antigen ( $\mathrm{HBeAg}$ ) and anti-HBe by immunodiffusion and by solid-phase RIA (HBeAg-Test: Abbott Laboratories) and for hepatitis B virus-specific DNA polymerase using $\left[{ }^{3} \mathrm{H}\right]$ thymidine according to a modification of the method of Kaplan et al. (13).

Immunoglobulin measurements. Total IgG and IgM concentrations were measured in culture supernatants using a microtiter-plate, enzyme-linked immunoassay (ELISA) (14). Microtiter plates were coated with antibody by adding 100 $\mu \mathrm{l}$ of either $10 \mu \mathrm{g} / \mathrm{ml}$ of goat anti-human $\mathrm{F}\left(\mathrm{ab}^{\prime}\right)_{2}$ or $10 \mu \mathrm{g} /$ $\mathrm{ml}$ of goat anti-human $\mu$-chain (N. L. Cappel Laboratories, Cochranville, PA) in carbonate buffer (pH 9.6) to each well The plates were incubated at $4^{\circ} \mathrm{C}$ overnight and then washed with $0.05 \%$ Tween-20 in phosphate-buffered saline (pH 7.4) $100 \mu \mathrm{l}$ of dilutions of test samples as well as standard control reagents were then added in duplicate and incubated at room temperature for $2 \mathrm{~h}$. After rewashing, $100 \mu \mathrm{l}$ of goat antihuman IgG or IgM (Fc fragment specific) conjugated to alkaline phosphatase (Sigma Chemical Co., St. Louis, MO) was added to detect IgG or IgM, respectively. The plates were incubated at room temperature for $2 \mathrm{~h}$ and then $100 \mu \mathrm{l}$ of $1 \mathrm{mg} / \mathrm{ml} p$-nitrophenyl phosphate in carbonate buffer $(\mathrm{pH}$ 8.0) containing $0.001 \mathrm{M} \mathrm{MgCl}_{2}$ was added to each well. Light absorbance was measured at $405 \mathrm{~nm}$ in a Microelisa MR 580 spectrophotometer (Dynatech Laboratories, Inc., Santa Monica, CA). Absorbance by wells that contained test samples was expressed as nanograms of IgG or IgM by reference to a standard curve constructed by linear regression analysis. Standard curves were linear in the range of 5 to $80 \mathrm{ng}$ for
IgG and 2.5 to $180 \mathrm{ng}$ for IgM. No cross-reactivity was found either for monoclonal IgM in the IgG assay or for IgG (Cohn fraction II) in the IgM assay. IgG and IgM concentrations in serum were measured by radial immunodiff usion (Meloy Laboratories, Inc., Springfield, VA).

Statistical analyses. Geometric means were calculated for immunoglobulin and antibody synthesis by control and carrier groups. The significance of differences between groups was determined by either Student's unpaired $t$ test or by chi square analysis.

\section{RESULTS}

\section{Synthesis of immunoglobulins and of antibodies to hepatitis B virus by unseparated lymphocytes}

PBMC isolated from 29 chronic HBsAg carriers and from 20 control subjects were cultured with PWM for 10 days. Culture supernatants were then assayed for IgG, IgM, anti-HBs, and anti-HBc.

PBMC from chronic $\mathrm{HBsAg}$ carriers and from control individuals synthesized similar amounts of total IgG and IgM after PWM stimulation (Fig. 1). These results indicated that $\mathrm{PBMC}$ from $\mathrm{HBsAg}$ carriers did not have an overall defect in response to PWM activation or in resultant immunoglobulin synthesis (15).

There were, however, differences between PBMC from chronic HBsAg carriers and controls in their production of specific antibodies to hepatitis B virus. Anti$\mathrm{HBc}$ was detected in culture supernatants from 21 of 29 (72\%) chronic HBsAg carriers but from only 2 of $20(10 \%)$ control individuals (all of whom had detect-

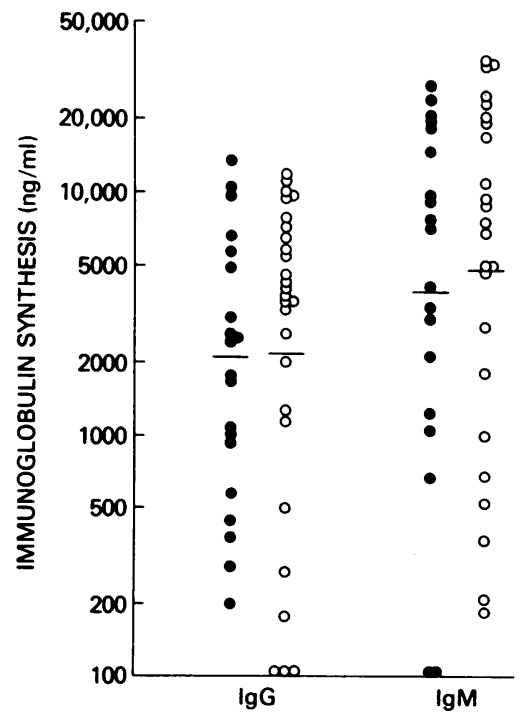

Figure 1 IgG and IgM levels in supernatants of PWM stimulated PBMC from 20 controls $(\bullet)$ and 27 chronic $\mathrm{HBsAg}$ carriers $(O)$ after $10 \mathrm{~d}$ of culture. Horizontal bars denote group means. 


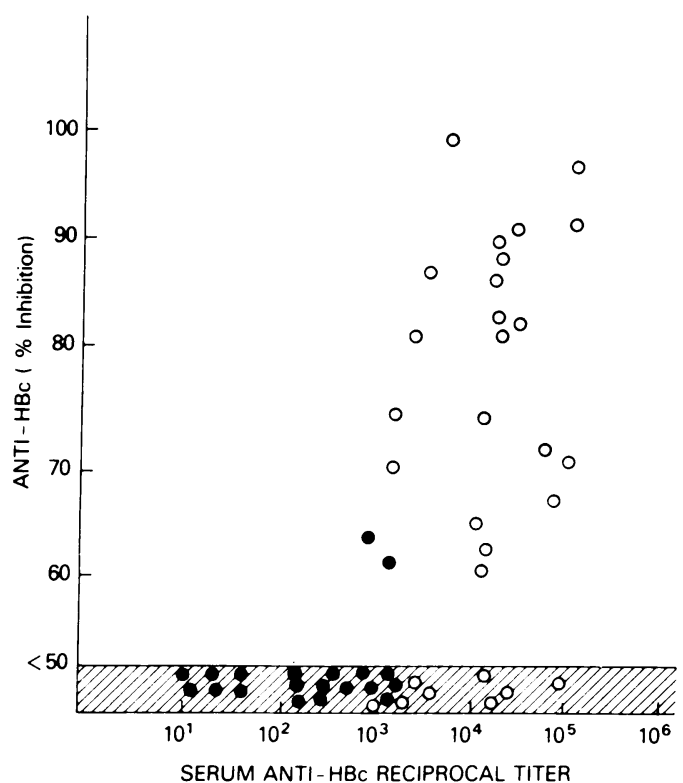

Figcre 2 Correlation between serum titers of anti-HBC and anti-HBc levels in supernatants of PWM-stimulated PBMC from 20 control individuals $(\bullet)$ and 29 chronic HBsAg carriers (O). Anti-HBc levels in supernatants are expressed as percent inhibition by blocking radioimmunoassay $(>50 \%$ is positive).

able serum levels of anti-HBc). The two controls whose lymphocytes produced anti-HBc in culture had both recovered from acute type $B$ hepatitis within 6 mo of testing. This difference in anti-HBc synthesis between carriers and controls was statistically significant $(P$ $<0.05)$ and appeared to be related to the higher titers of anti-HBc in serum of carriers (geometric mean titer 1:14,000) vs. controls (geometric mean titer 1:300).
The relationship between serum anti-HBc titer and the in vitro synthesis of this antibody by lymphocytes is shown in Fig. 2.

Not all HBsAg carriers synthesized anti-HBc in vitro. Comparison of patients who did synthesize anti$\mathrm{HBc}$ with those who did not failed to reveal any clinical or serologic differences between the two groups (data not shown). The mean serum titer of anti-HBc and mean serum levels of $\operatorname{IgG}$ and $\operatorname{IgM}$ were similar in the two groups (Table I). However, the total IgG and IgM synthesis in vitro by lymphocytes of carriers who did not synthesize anti-HBc in culture was on average less than that by lymphocytes from carriers who did produce anti-HBc in culture.

In general, four to six replicates of each culture were performed. A high proportion of replicate cultures from the 21 chronic carrier responders were anti-HBc positive $(85 \%)$, suggesting that these individuals had a high frequency of precursor cells capable of producing anti-HBc.

In contrast to anti-HBc, anti-HBs was not detected in any supernatant of PBMC from the 29 chronic HBsAg carriers (Fig. 3). Several carriers were tested on multiple occasions using up to 10 replicate cultures on each individual. Supernatants were tested using both solid-phase RIA and radioimmunoprecipitation techniques. Anti-HBs was absent from all carrier lymphocyte supernatants. In contrast, anti-HBs was detected in lymphocyte supernatants from 6 of 20 control individuals. All 20 controls tested possessed serum antiHBs. Titers of serum anti-HBs in the six anti-HBs "responders" ranged from 1:140 to 1:15,000 (geometric mean 1:6,373); while titers in the 14 "nonresponders" ranged from $1: 10$ to $1: 12,000$ (geometric mean $1: 1055$ ) (Fig. 4). Four of the six responders had recently received a booster injection of hepatitis $B$ virus

TABLE: I

Comparison of Chronic HBsAg Carriers Whose Lymphocytes Produced Anti-HBc with Those Whose Lymphocytes Did Not Produce Anti-HBc In Vitro

\begin{tabular}{|c|c|c|c|c|c|c|}
\hline \multirow[b]{2}{*}{ Group } & \multirow[b]{2}{*}{ No. } & \multicolumn{3}{|c|}{ Serum levels of } & \multicolumn{2}{|c|}{ Culture supernatants levels of } \\
\hline & & Anti-HBc ${ }^{\circ}$ & $\lg 6 t$ & $\lg M t$ & $\lg G^{\circ}$ & $\lg M^{\bullet}$ \\
\hline & & titer & \multicolumn{2}{|c|}{$m g / d l$} & \multicolumn{2}{|c|}{$n g / m l$} \\
\hline $\begin{array}{l}\text { Positive } \\
\text { anti-HBC }\end{array}$ & 21 & $\begin{array}{c}1: 4,800 \\
(1: 4,000-1: 6,000)\end{array}$ & $\begin{array}{l}1,525 \\
( \pm 98)\end{array}$ & $\begin{array}{c}155 \\
( \pm 16)\end{array}$ & $\begin{array}{c}4,036 \\
(2,993-5,443)\end{array}$ & $\begin{array}{c}8,214 \\
(5,843-11,546)\end{array}$ \\
\hline \multirow[t]{2}{*}{$\begin{array}{l}\text { Negative } \\
\text { anti-HBc }\end{array}$} & 8 & $\begin{array}{c}1: 2,800 \\
(1: 2,300-1: 3,400)\end{array}$ & $\begin{array}{c}1,525 \\
( \pm 246)\end{array}$ & $\begin{array}{c}131 \\
( \pm 20)\end{array}$ & $\begin{array}{c}528 \\
(278-1,002)\end{array}$ & $\begin{array}{c}1,120 \\
(516-2,434)\end{array}$ \\
\hline & & $\mathrm{NS}$ & NS & NS & $P<0.05$ & $P<0.05$ \\
\hline
\end{tabular}

- Geometric mean ( \pm 1 SEM from logarithmic mean).

\pm Mean $( \pm$ SEM). 


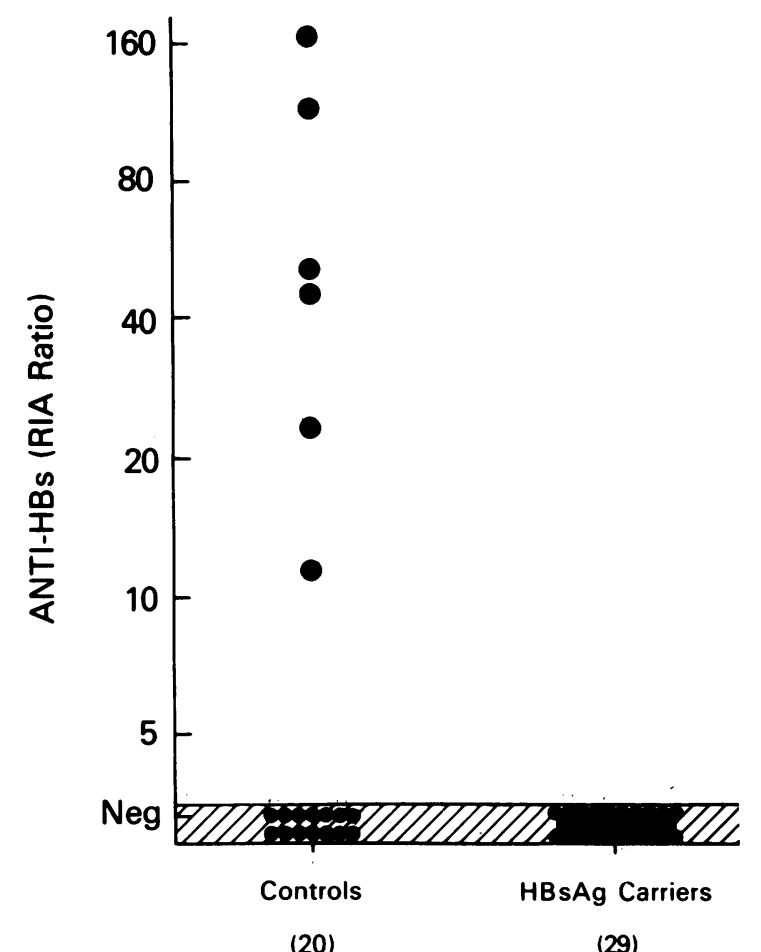

Figure 3 Anti-HBs levels in supernatants of PWM-stimulated PBMC from 20 control individuals and 29 chronic $\mathrm{HBsAg}$ carriers. Anti-HBs levels are expressed as a ratio of the test sample to negative control counts per minute by radioimmunoassay ( $>2.1$ is positive).

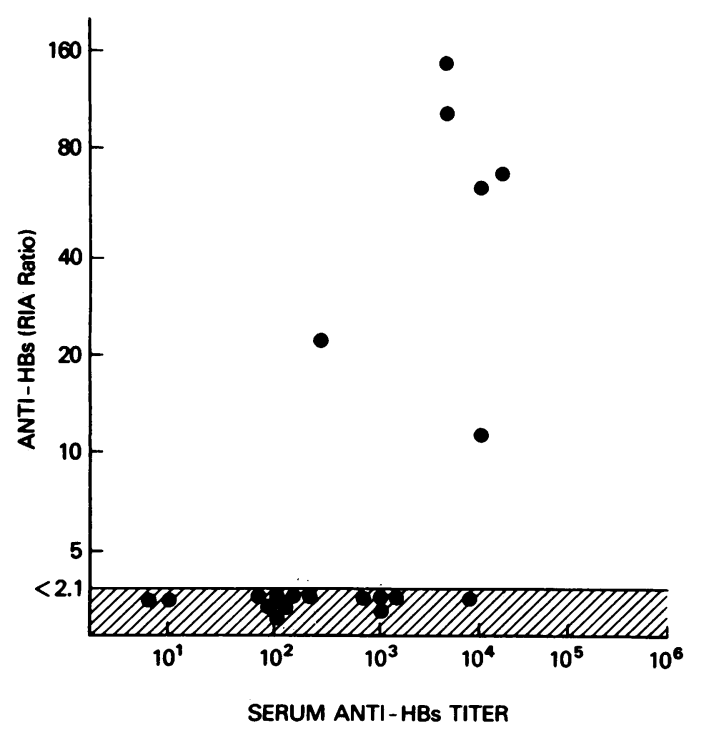

Figure 4 Correlation between serum titers of anti-HBs and anti-HBs levels in supernatants of PWM-stimulated PBMC from 20 control individuals. vaccine (two of whom had failed to synthesize antiHBs in vitro before the booster inoculation). Two other controls whose cells produced anti-HBs in vitro, had never received vaccine.

Multiple replicate cultures were performed on each control. Although total IgG and IgM synthesis per 2 $\times 10^{6}$ cells remained constant in replicate cultures from each individual, the quantity of anti-HBs in each supernatant of cultured cells from the same individual varied greatly, indicating a random, independent distribution of precursor B cells for anti-HBs synthesis. In general, only $20-80 \%$ of cultures from responder individuals were anti-HBs positive. PBMC from one responder control were sampled over a 12-mo period of time. The fraction of replicate cultures positive for anti-HBs gradually decreased (from 80 to $20 \%$ ) as titers of serum anti-HBs fell (from 1:9,000 to $1: 120$ ).

Supernatants from PBMC not stimulated with PWM produced little or no IgG and IgM and were never positive for either anti-HBs or anti-HBc. Furthermore, anti-HBs and anti-HBc synthesis by PBMC was never detectable after $1 \mathrm{~d}$ of culture. These features exclude the possibility of passive "carry over" of cytophilic antibody from the initial blood sample as a cause for the positive antibody results in these cultures. In these and subsequent experiments the binding of anti-HBs to passively carried-over $\mathrm{HBsAg}$ from the initial blood specimen was excluded by the absence of detectable HBsAg in supernatants and by the absence of blocking of anti-HBs in positive control supernatants by supernatants from carriers.

Supernatants of PBMC cultures from five chronic $\mathrm{HBs} A \mathrm{~g}$ carriers who possessed anti-HBe in serum were tested for anti-HBe. None were positive.

\section{Co-culture experiments}

The nature of the defect in anti-HBs synthesis by PBMC from chronic HBsAg carriers was further evaluated by conducting cell mixing experiments. Persons whose PBMC had been shown to synthesize anti-HBs in culture were subjected to lymphopheresis and their cells were cryopreserved in liquid nitrogen in order to have adequate numbers of responder (anti-HBs synthesizing) B lymphocytes for these experiments. In coculture experiments, the supernatants from triplicate cultures were pooled for anti-HBs measurements.

Co-culture of allogeneic unseparated lymphocytes. $\operatorname{PBMC}\left(1 \times 10^{6}\right)$ from a single anti-HBs responder were cultured in the presence of unseparated PBMC (1 $\times 10^{6}$ ) from 5 control (both responder and nonresponder) individuals and from 11 chronic HBsAg carriers. Anti-HBs synthesis was observed in each of the control co-cultures, but was detected in only 4 of the 11 cultures containing HBsAg carrier PBMC (Fig. 5). How- 


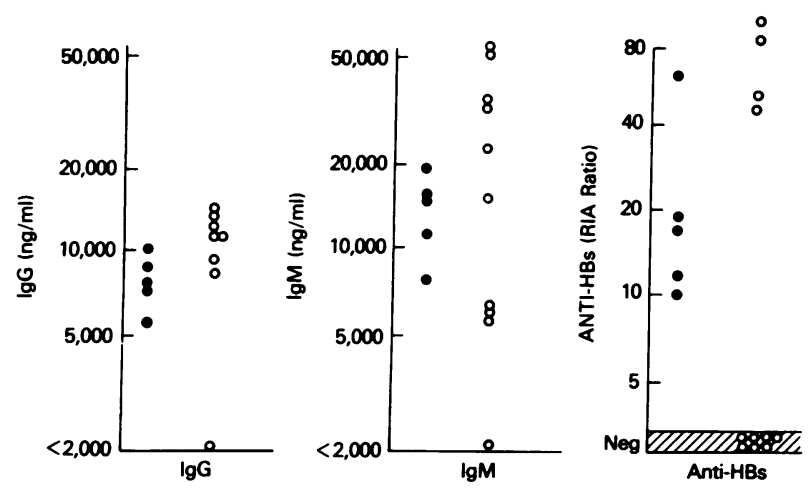

Figure 5 IgG, IgM and anti-HBs levels in supernatants of co-cultures of PBMC from either control individuals $(\bullet)$ or chronic HBsAg carriers (O) with allogeneic PBMC from "responder" (anti-HBs-producing) controls. A marked and specific suppression of anti-HBs production was noted with 7 of the 11 co-cultures with carrier PBMC.

ever, the total IgG and IgM synthesis by the control co-cultures was similar to that by the $\mathrm{HBsAg}$ carrier co-cultures. These data suggested that some chronic $\mathrm{HBsAg}$ carriers may have a defect in immunoregulation characterized by suppressor activity that specifically impairs anti-HBs production by responder PBMC.

Co-culture of allogeneic irradiated T lymphocytes with responder $B$ lymphocytes. To assess whether $T$ lymphocytes from chronic HBsAg carriers were defective in augmenting anti-HBs production by responder B lymphocytes, further co-culture experiments were performed. Irradiated $T$ lymphocytes from either control individuals or from chronic $\mathrm{HBsAg}$ carriers were cultured with allogeneic responder $B$ lymphocytes (i.e. B cells capable of synthesizing antiHBs) from three different control individuals. The time course of synthesis of anti-HBs and IgG by responder B lymphocytes co-cultured with and without irradiated allogeneic $T$ cells is shown in Fig. 6. AntiHBs synthesis was not detected and IgG production was minimal in the absence of $\mathrm{T}$ lymphocytes. However, in the presence of control irradiated T lymphocytes, responder $\mathrm{B}$ cells produced detectable amounts of anti-HBs and IgG between days 4 and 8 of culture. In a total of 16 experiments, responder B lymphocytes co-cultured with irradiated $\mathrm{T}$ lymphocytes from allogeneic controls invariably synthesized anti-HBs, which was detectable in culture supernatants. These control $\mathrm{T}$ cells provided helper function regardless of whether they were obtained from anti-HBs responder or nonresponder individuals. However, when these responder B lymphocytes were co-cultured with irradiated $\mathrm{T}$ lymphocytes from chronic $\mathrm{HBsAg}$ carriers, anti-HBs production was not always detected. In 24 experiments, anti-HBs was detectable in co-culture

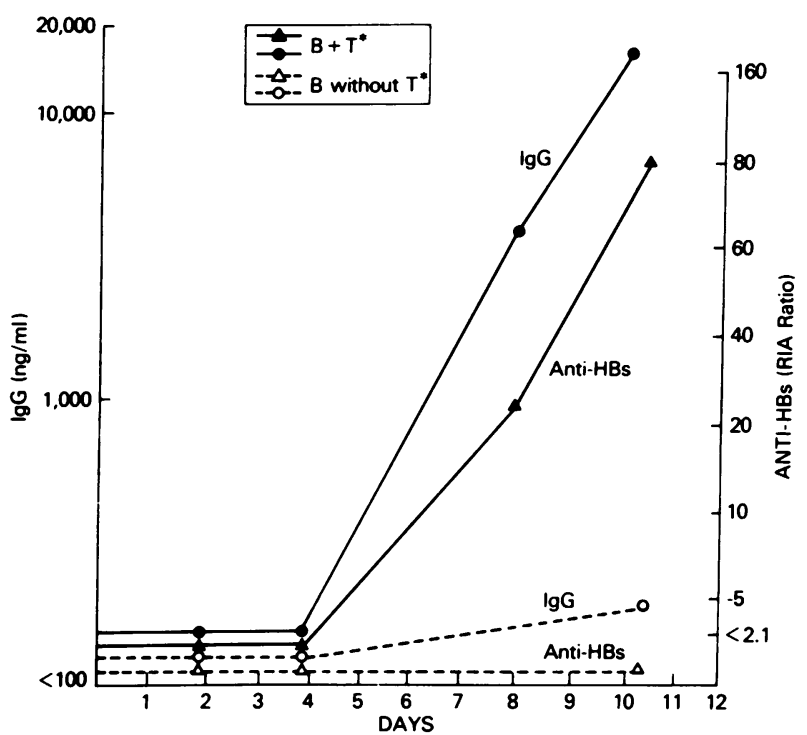

Figure 6 Time course of production of IgG and anti-HBs by PWM-stimulated "responder" $B$ cells with and without irradiated $\mathrm{T}$ cells.

supernatants from 16 chronic HBsAg carriers (Fig. 7). Irradiated $\mathrm{T}$ lymphocytes from the remaining eight carriers failed to augment anti-HBs synthesis. Total immunoglobulin synthesis by PBMC was similar regardless of the source of irradiated $T$ lymphocytes and regardless of whether anti-HBs was detectable. These experiments suggested that some chronic $\mathrm{HBsAg}$ carriers exhibited a specific defect in helper $\mathrm{T}$ lymphocyte augmentation of anti-HBs production.

Co-culture of allogeneic T lymphocytes with control $B$ and irradiated $T$ lymphocytes. Suppressor T cell function was assessed in co-culture experiments by mixing $\mathrm{T}$ lymphocytes from controls or chronic HBsAg carriers with a combination of B lymphocytes and irradiated $T$ lymphocytes from responder control individuals. The combination of control irradiated $T$ lymphocytes and control B lymphocytes had been shown to invariably result in anti-HBs synthesis. Thus, the addition of non-irradiated $\mathrm{T}$ lymphocytes to this combination would permit an assessment of active suppression of anti-HBs synthesis. When control $T$ lymphocytes were co-cultured with B lymphocytes and irradiated $T$ lymphocytes from responders, no suppression of either immunoglobulin or anti-HBs production occurred (Fig. 8). However, in experiments using $T$ lymphocytes from 12 chronic HBsAg carriers, active suppression of anti-HBs production was sometimes observed. T lymphocytes from 7 of the 12 carriers did not suppress IgG, IgM, or anti-HBs synthesis. T lymphocytes from the remaining five chronic $\mathrm{HBsAg}$ carriers, however, suppressed anti-HBs production, and $T$ lymphocytes from two of these five caused moderate 

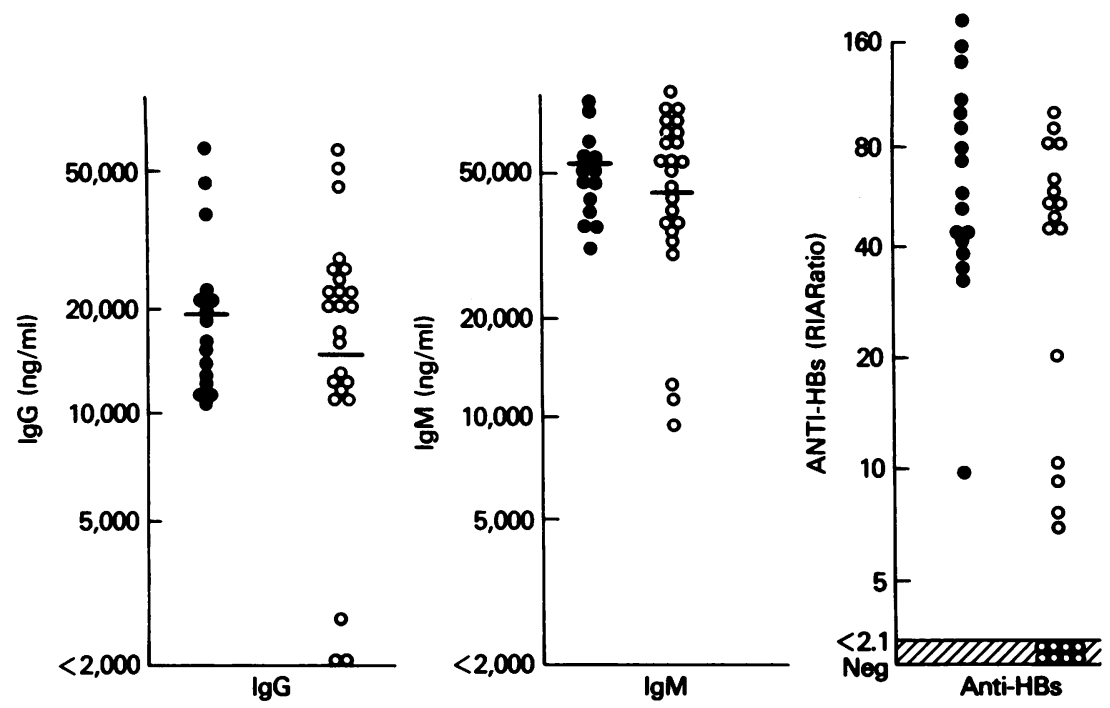

Figure 7 IgG, IgM, and anti-HBs levels in supernatants of co-cultures of irradiated $\mathrm{T}$ cells of either controls $(\Theta)$ or carriers $(O)$ with PWM-stimulated B cells of a responder control individual. These co-culture experiments were designed to assess specific helper $\mathrm{T}$ lymphocyte function.

suppression of IgG and IgM synthesis. These results suggested that a proportion of $\mathrm{HBsAg}$ carriers have $\mathrm{T}$ lymphocytes that can actively suppress anti-HBs production in vitro.

Co-culture of B lymphocytes from chronic HBsAg carriers and irradiated $T$ lymphocytes of control individuals. B lymphocyte function of chronic $\mathrm{HBsAg}$ carriers was assessed in a series of co-culture experi- ments. B lymphocytes from nine chronic $\mathrm{HBsAg}$ carriers were cultured with irradiated $\mathrm{T}$ lymphocytes from allogeneic control individuals. These chronic carriers were selected in that their unseparated PBMC had previously been demonstrated to synthesize anti$\mathrm{HBc}$ in vitro. The cultures were designed to maximize $\mathrm{T}$ helper activity and to eliminate any suppressor cell influences. Substantial amounts of IgG (mean 18,980
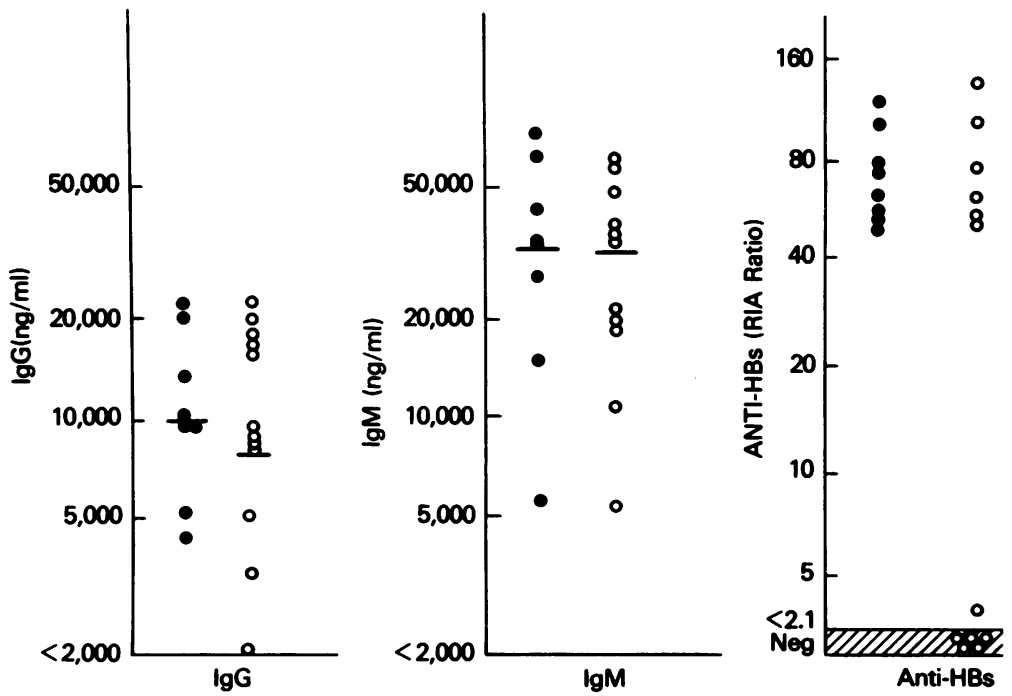

Figure 8 IgG, IgM, and anti-HBs levels in supernatants of co-cultures of $T$ cells from either controls $(\bullet)$ or chronic carriers $(O)$ with a combination of irradiated T cells and PWM-stimulated B cells from a responder control individual. These co-culture experiments were designed to assess suppressor $\mathrm{T}$ lymphocyte function. 

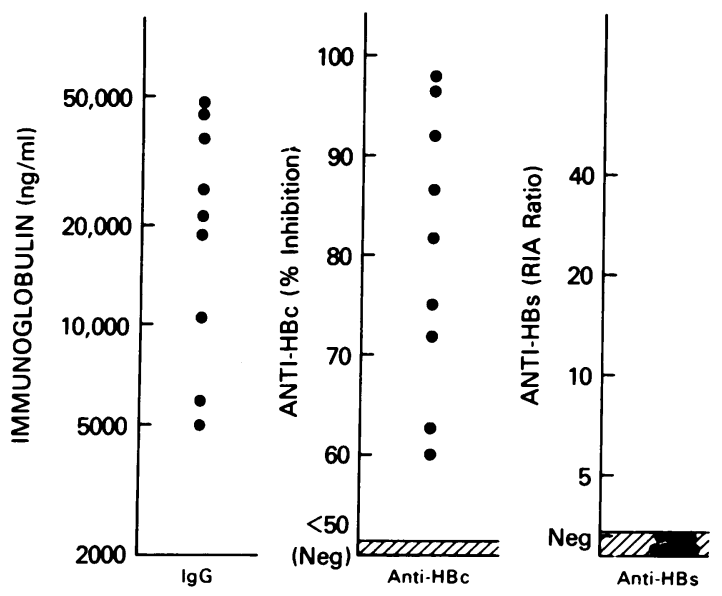

Figure 9 IgG, anti-HBc, and anti-HBs levels in supernatants of co-cultures of PWM stimulated B cells from chronic carriers with irradiated $T$ cells from control responder individuals. These co-culture experiments were designed to assess B lymphocyte function.

$\mathrm{ng} / \mathrm{ml}$ ) and $\mathrm{IgM}$ (mean $23,319 \mathrm{ng} / \mathrm{ml}$ ) were produced in these allogeneic cultures (Fig. 9). Furthermore, all cultures synthesized detectable amounts of anti-HBc. Nevertheless, no anti-HBs production by the chronic HBsAg carrier B lymphocytes was detected despite the addition of maximal helper $T$ cell influences. These results suggested that $B$ lymphocytes from chronic HBsAg carriers have a specific defect in anti-HBs production.

\section{DISCUSSION}

These experiments were designed to investigate why chronic HBsAg carriers fail to produce detectable amounts of anti-HBs, despite a continuous exposure to high serum levels of HBsAg. To study this question, in vitro PWM stimulation of antibody synthesis was selected as a model system. This mitogen activates both $B$ cells and helper $T$ cells, leading to antibody synthesis, and also activates suppressor $\mathrm{T}$ cells, which inhibit antibody synthesis (16). Thus, the major elements of the normal humoral immune response can be investigated with this system. The results of these studies indicate that the PBMC of chronic HBsAg carriers produce levels of polyclonal IgG and IgM similar to those of normal control individuals who had recovered from type B hepatitis. These results, therefore, are compatible with other studies that have shown normal or only minimally abnormal humoral and cell-mediated immunity in chronic HBsAg carriers as assessed by humoral antibody responses, total serum immunoglobulin levels, skin test antigen reactivity, mitogeninduced blastogenesis, and regulatory $T$ cell responsiveness $(5,6,17-23)$. This supports the concept that if an immunologic deficiency underlies the development of the chronic HBsAg carrier state, it must involve either a very specific immunologic mechanism (as yet unknown) or an immunologic response to a specific antigen.

We attempted to assess specific immunologic responsiveness in chronic $\mathrm{HBsAg}$ carriers by measuring the ability of their lymphocytes to synthesize not only IgG and IgM, but also specific antibodies to hepatitis $B$ virus antigens. The lymphocytes from the majority of chronic HBsAg carriers were found to synthesize anti-HBc in culture. In contrast, these same chronic carrier lymphocytes did not produce detectable amounts of anti-HBs, despite the fact that they are constantly exposed to HBsAg in vivo. These results suggest that chronic $\mathrm{HBsAg}$ carriers have a specific inability to generate an antibody response to $\mathrm{HBsAg}$. On the basis of co-culture experiments, the basis of this abnormality appeared to be a specific inability of chronic carrier B cells to synthesize anti-HBs, rather than a defect in helper or suppressor $T$ cell function.

The inability of chronic carrier PBMC to produce anti-HBs in culture, however, should be interpreted keeping in mind the limitations of this test system. In these same studies, we have shown that lymphocytes from a majority of persons who have recovered from type $B$ hepatitis and who have detectable levels of serum anti-HBs, also do not produce anti-HBs in culture. Indeed, the synthesis of anti-HBs by PBMC in culture was found only in individuals with high serum titers of this antibody. Lymphocytes from those control individuals with serum anti-HBs titers of $1: 1,000$ or less usually did not produce anti-HBs in culture; PBMC from those persons with higher serum anti-HBs titers usually did synthesize anti-HBs in cultures (Fig. 4). Exceptions to this could be explained by the finding of either generalized hyper- or hyporesponsiveness of PBMC to PWM stimulation of immunoglobulin synthesis.

Serum titers of antibody also predicted which persons produced anti-HBc in lymphocyte cultures. In general, only the PBMC from those persons with serum anti-HBc titers of $1: 1,000$ or greater could be shown to synthesize anti-HBc in vitro. Thus, the presence of anti-HBc and the absence of anti-HBs in supernatants of PBMC from chronic HBsAg carriers reflected the high serum titers of anti-HBc and low or absent serum titers of anti-HBs found in most carriers.

The absence of an anti-HBs response in chronic HBsAg carriers still requires explanation. Actually, a percentage of $\mathrm{HBsAg}$ carriers (33\% in this study) do have detectable amounts of serum anti-HBs. Studies have shown, however, that this anti-HBs is heterotypic, i.e., it is directed against subdeterminants of $\mathrm{HBsAg}$ that are not present in that serum (7). This heterotypic antibody is also present in low titer. 
One explanation for the lack of detectable serum anti-HBs in chronic HBsAg carriers is that any homotypic antibody produced would quickly be absorbed to the large quantities of circulating $\mathrm{HBsAg}$ (which can be present in amounts of up to $500 \mu \mathrm{g} / \mathrm{ml}$ ). Indeed, several groups of investigators have reported the finding of immune complexes of HBsAg and antiHBs in serum or tissue of patients with chronic type $B$ hepatitis and these immune complexes are thought to play a role in the extrahepatic manifestations of this disease (24-28). However, the specificity of the tests for detecting anti-HBs in the presence of high levels of $\mathrm{HBsAg}$ has not been well documented. Results in this study strongly suggest that chronic HBsAg carriers do not produce homotypic anti-HBs. Despite several manipulations designed to increase the sensitivity of the tests to detect anti-HBs, to maximize antibody production and to remove any suppressor activity, no anti$\mathrm{HBs}$ production by lymphocytes of any chronic $\mathrm{HBsAg}$ carrier was detected. A broad spectrum of HBsAg-positive patients was studied, including two with polyarteritis nodosa.

Another explanation for the absence of detectable anti-HBs synthesis by chronic HBsAg carrier lymphocytes is the presence of abnormal immunoregulatory lymphocytes. This possibility was suggested by results of the initial co-culture experiments using unseparated PBMC from carriers and from anti-HBs producing control individuals. Further analysis of $\mathrm{T}$ lymphocyte function, however, revealed a heterogenous group of regulatory defects. Thus, one third of carriers studied appeared to have a defect in helper $\mathbf{T}$ cell augmentation of anti-HBs production and $41 \%$ of carriers demonstrated an enhanced suppressor $\mathrm{T}$ cell activity that decreased anti-HBs production. The presence of these abnormalities did not correlate with the clinical status or degree of chronic hepatitis disease activity in these patients. It should be emphasized that in these experiments helper $\mathrm{T}$ cell activation was assessed by stimulation with PWM rather than specific antigen. In this regard it must be questioned whether the $T$ cell defect is one of failure to provide an antigen-specific helper signal or a more generalized defect (perhaps in the activation of all memory $B$ cells); indeed, a recent preliminary report suggests that T cells in PWM-stimulated systems activate B cells in a nonspecific manner (29). The existence of an antigen-specific $T$ cell defect could possibly be demonstrated using specific antigen (HBsAg) to activate the $\mathrm{T}$ cells, in a manner similar to the specific activation of $T$ cells by tetanus toxoid (30).

For several reasons, the regulatory $\mathrm{T}$ cell abnormalities described in this study do not adequately explain the absence of an anti-HBs response in chronic HBsAg carriers. First, the role of histocompatibility or allogeneic differences between the $T$ cells being analyzed and the B cells used as indicator anti-HBs synthesizing lymphocytes could not be assessed (31, 32). Selected specific immune responses may be more sensitive to nonspecific allogeneic suppressor $T$ cell activity or be less sensitive to allogeneic helper $T$ cell activity. Second, the independent effect of suppressor monocytes (which are radiation resistant) was not evaluated $(33,34)$. Third, the presence of specific suppressor cell activity is not unexpected as such activity is commonly seen after primary and secondary immunization (35). Finally, co-culture experiments demonstrated that despite elimination of suppressor $\mathrm{T}$ cell activity and despite provision of maximal helper $\mathrm{T}$ cell function, B lymphocytes from chronic HBsAg carriers still did not produce detectable anti-HBs.

Thus, the major immunologic defect of chronic HBsAg carriers found in this study was an absence of circulating B cells capable of synthesizing anti-HBs. What is not clear from these experiments is whether anti-HBs producing lymphocytes are totally absent or are merely low in number, whether they are not present in the body or are sequestered (perhaps in the liver or the spleen), and whether they are deleted or are held in an inactive state, rendered tolerant perhaps by the presence of excess circulating HBsAg. This final possibility is particularly attractive. Several groups of investigators have shown that the in vitro proliferation of specific antibody producing $B$ cells and secretion of antibody can be blocked by the presence of excess antigen (14, 36-38). A similar explanation might account for the lack of serum anti-HBs in chronic HBsAg carriers. Indeed, the absence of anti-HBs synthesis by chronic HBsAg carrier lymphocytes may not actually be a defect in immunologic function as much as a normal regulatory mechanism by which the immune system avoids producing antibodies to antigens present in high concentrations. The present experiments do not address these possibilities but do help to dissect the complex immunoregulatory network that modulates specific antibody synthesis in this disease.

\section{ACKNOWLEDGMENTS}

We are indebted to Dr. Vincent McAuliffe and Dr. Robert Purcell for providing hepatitis B virus vaccine, to Dr. David Volkmann and Dr. Robert Yarchoan for advice and encouragement, and to Mrs. Jeanne Waggoner for technical assistance.

\section{REFERENCES}

1. Hoofnagle, J. H. 1981. Type B hepatitis. Serology, virology and clinical course. Semin. Liver Dis. 1: 6-13.

2. Dudley, F. J., R. A. Fox, and S. Sherlock. 1972. Cellular immunity and hepatitis-associated, Australia antigen liver disease. Lancet. I: 723-726.

3. Serjeantson, S., and D. G. Woodfield. 1978. Immune re- 
sponse of leprosy patients to hepatitis B virus. Am. J. Epidemiol. 107: 321-327.

4. Blumberg, B. S., A. I. Sutnick, and W. T. London. 1970. Australia antigen as a hepatitis virus. Variation in host response. Am. J. Med. 48: 1-8.

5. Chisari, F. V., J. A. Routenberg, D. S. Anderson, and T. S. Edgington. 1978. Cellular immune reactivity in HBV-induced disease. In Viral Hepatitis. G. N. Vyas, S. N. Cohen, and R. Schmid, editors. Franklin Institute Press, Philadelphia. 245-266.

6. Tong, M. J., A. M. Wallace, R. L. Peters, and T. B. Reynolds. 1975. Lymphocyte stimulation in hepatitis B infections. N. Engl. J. Med. 293: 318-322.

7. Tabor, E., R. J. Gerety, L. A. Smallwood, and L. F. Barker. 1977. Coincident hepatitis B surface antigen and antibodies of different subtypes in human serum. J. Immunol. 118: 369-370.

8. Purcell, R. H., and J. L. Gerin. 1978. Hepatitis B vaccines. On the threshold. Am. J. Clin. Pathol. 70: 159169

9. Boyum, A. 1976. Isolation of lymphocytes, granulocytes and macrophages. Scand. J. Immunol. 5(Suppl.): 9-15.

10. James, S. P., C. O. Elson, E. A. Jones, and W. Strober. 1980. Abnormal regulation of immunoglobulin synthesis in primary biliary cirrhosis. Gastroenterology. 79: 242254

11. Siegal, F. P., and M. Siegal. 1977. Enhancement by irradiated $T$ cells of human plasma cell production. Dissection of helper and suppressor functions in vitro. $J$. Immunol. 118: 642-647.

12. Lander, J. J., H. J. Alter, and R. H. Purcell. 1971. Frequency of antibody to hepatitis associated antigen as measured by a new radioimmunoassay technique. J. Immunol. 106: 1166-1171.

13. Kaplan, P. M., R. L. Greenman, J. L. Gerin, R. H. Purcell, and W. S. Robinson. 1973. DNA polymerase associated with human hepatitis B antigen. J. Virol. 12: 9951005.

14. Volkman, D. J., H. C. Lane, and A. S. Fauci. 1981. Antigen-induced in vitro antibody production in humans: a model for $B$ cell activation and immunoregulation. Proc. Natl. Acad. Sci. USA. 78: 2528-2531.

15. Mutnick, M. G., H. M. Lederman, A. Missinan, and A. G. Johnson. 1981. In vitro synthesis of IgG by peripheral blood lymphocytes in chronic liver disease Clin. Exp. Immunol. 43: 370-375.

16. Chess, L., R. P. MacDermott, and S. F. Schlossman. 1974 Immunologic functions of isolated human lymphocyte populations. I. Quantitative isolation of human T and $B$ cells and response to mitogens. J. Immunol. 113: $1113-$ 1121

17. Sutnick, A. I., S. J. Bugbee, W. T. London, L. A. Loeb F. Peyretti, S. Litwin, and B. S. Blumberg. 1973. Lymphocyte function in normal people with Australia antigen. J. Lab. Clin. Med. 82: 79-85.

18. Bolin, T. D., A. E. Davis, and A. G. Liddelow. 1973. Liver disease and cell mediated immunity in hepatitisassociated antigen (HAA) carriers. Gut. 14: 365-368.

19. Nielson, J. O., V. Reinicke, O. Dietrichson, V. Andersen, M. Thomsen, and E. Andersen. 1973. Immunological studies of Australia antigen carriers with and without liver diseases. Clin. Exp. Immunol. 15: 9-16.

20. Desaules, M., P. C. Frei, J. Libanska, and B. Wuilleret. 1976. Lack of leukocyte migration inhibition by hepatitis $B$ antigen and normal non-specific immunoreactivity in asymptomatic carriers. J. Infect. Dis. 134: 505-509.

21. Aldershvile, J., O. Dietrichson, F. Hardt, J. O. Nielsen, and P. Skinhoj. 1977. Humoral and cell mediated immunity to hepatitis B virus antigens in acute and chronic liver disease. Scand. J. Gastroenterol. 12: 917-922.

22. Feighery, C., J. F. Greally, and D. G. Weir. 1980. Mitogen responsiveness in viral hepatitis. The role of reversible suppressive influences. Gut. 21: 738-744.

23. Levo, Y., D. Shouval, R. Tur-Kaspa, S. Wollner, S. Penchas, A. Zlotnick, and M. Eliakim. 1981. Immunological evaluation of asymptomatic carriers of hepatitis B virus. Clin. Exp. Immunol. 44: 63-67.

24. Almeida, J. D., and A. P. Waterson, 1969. Immune complexes in hepatitis. Lancet. II: 983-986.

25. Shulman, N. R., and L. F. Barker. 1969. Virus-like antigen, antibody and antigen-antibody complexes in hepatitis measured by complement fixation. Science (Wash. DC). 165: 304-306.

26. Gocke, D. J. 1978. Immune complex phenomena associated with hepatitis. In Viral Hepatitis. G. N. Vyas, S. N. Cohen, and R. Schmid, editors. Franklin Institute Press, Philadelphia. 277-283.

27. Madalinski, K., A. Sztachelska-Budkowska, and W. J. Brzosko. 1974. DEAE-cellulose chromatography. A method for dissociation of soluble immune complexes of hepatitis B surface antigen. J. Infect. Dis. 129: 371375.

28. Wands, J. R., E. Mann, E. Alpert, and K. J. Isselbacher 1975. The pathogenesis of arthritis associated with acute hepatitis B surface antigen positive hepatitis. J. Clin. Invest. 55: 930-936.

29. Lane, H. C., G. Whalen, and A. S. Fauci. 1982. Dichotomy between antigen and mitogen-induced $T$ cell help in human B cell activation. Clin. Res. 30: 352a. (Abstr.)

30. Mudawwar, F. B., E. J. Yunis, and R. S. Geha. 1978. Antigen-specific helper factor in man. J. Exp. Med. 148: 1032-1043.

31. Rumke, K. C., F. G. Terpstra, B. Huis, T. A. Out, and W. P. Zeijlemaker. 1982. Immunoglobulin production in human mixed lymphocyte cultures: Implications for co-cultures of cells from patients and healthy donors. $J$. Immunol. 128: 696-702.

32. Swain, S., P. E. Trefts, W. S. Tse, and R. W. Dutton. 1977. The significance of T-B collaboration across haplotype barriers. Cold Spring Harbor Symp. Quant. Biol. 41: 597-609.

33. Katz, P., and A. S. Fauci. 1978. Inhibition of polyclonal $B$ cell activation by suppressor monocytes in patients with sarcoidosis. Clin. Exp. Immunol. 32: 554-562.

34. Laughter, A. H., M. D. Lidsky, and J. J. Twomey. 1979. Suppression of immunoglobulin synthesis by monocytes in health and in patients with systemic lupus erythematosus. Clin. Immunol. Immunopath. 14: 435-440.

35. Stevens, R. H., and A. Saxon. 1978. Immunoregulation in humans. Control of anti-tetanus toxoid antibody production after booster immunization. J. Clin. Invest., 62: 1154-1160.

36. Schrader, J. W. 1975. Effector cell blockade. II. A demonstration of the reversible masking of an immune response by blocking of antibody forming cells. Eur. J. Immunol. 5: 808-812.

37. Stevens, R. H. 1981. Immunoglobulin bearing cells are a target for the antigen-induced inhibition of pokeweed mitogen stimulated antibody production. J. Immunol. 127: 968-972.

38. Diener, E., and M. Feldman. 1972. Mechanism at the cellular level during induction of high zone tolerance in vitro. Cell. Immunol. 5: 130-136. 